\title{
Temperature-modified density effects in the black soldier fly: low larval density leads to large size, short development time and high fat content
}

\author{
L.O. Opare ${ }^{1^{*}}$ iD, S. Holm ${ }^{1,2}$ iD and T. Esperk ${ }^{1}$ iD \\ ${ }^{1}$ Institute of Ecology and Earth Sciences, University of Tartu, Juhan Liivi 2, 50409 Tartu, Estonia; ${ }^{2}$ Department of \\ Environmental and Biological Sciences, University of Eastern Finland, P.O. Box 111, 80101 Joensuu, Finland; opare@ut.ee
}

Received: 24 August 2021 / Accepted: 22 November 2021

(c) 2022 Wageningen Academic Publishers

OPEN ACCESS CC (i) RESEARCH ARTICLE

\begin{abstract}
The effects of biotic and abiotic factors on insect life histories have been extensively studied. However, the impact of some crucial aspects, such as larval density (crowding) and the effects of environmental interactions, have often been overlooked. This study aims to determine the effects of larval density and temperature on life-history traits in the black soldier fly (BSF). Our results showed an increase in prepupal mass, pupal mass, prepupal-to-pupal mass loss, survival, prepupal fat content, adult mass, adult longevity and a reduction in larval and pupal development time at low densities. Larval density was maintained throughout the entire larval period and larval survival was determined at the $4^{\text {th }}$ instar and at prepupation. Larvae were reared at three different larval densities $(1,5$ and 10 larvae $\left./ \mathrm{cm}^{2}\right)$, at three temperature treatments $\left(23,27\right.$ and $\left.30^{\circ} \mathrm{C}\right)$ and food was provided ad libitum. High densities, on the contrary, resulted in an increase in development time, mortality and a decrease in prepupal mass loss. Temperature significantly affected all studied traits except survival, prepupal fat content and adult longevity, and notably modified the larval density effects on prepupal mass, pupal mass, adult mass, prepupal-to-pupal mass loss, prepupal fat content, duration of larval period, and adult longevity. Males and females differed in all studied lifehistory traits except adult mass. We conclude that density and temperature and their interaction-related effects during larval development considerably affect BSF larval life-history traits. Therefore, these effects should be carefully considered when planning for insect mass rearing.
\end{abstract}

Keywords: rearing density, thermal reaction norms, body size, edible insects, Hermetia illucens

\section{Introduction}

Insects are considered a promising and sustainable alternative to conventional food and feed production (Berggren et al., 2019; Van Huis and Oonincx, 2017). This is mainly because edible insects are found to have similar nutritional values when compared to traditional animals used for the production of meat (Barragan-Fonseca et al., 2017; Payne et al., 2016; Rumpold and Schlüter, 2013; Van Huis, 2013). Insects have higher feed conversion efficiencies (Oonincx et al., 2015; Wegier et al., 2018), lower emission of greenhouse gases (Berggren et al., 2019; Gravel and Doyen, 2020; Jonsson et al., 2013; Mertenat et al., 2019) and higher water efficiency (Nakagaki and Defoliart, 1991; Wegier et al., 2018) than traditional farm animals. For these reasons, insects are extensively studied to be used to feed fish (Liland et al., 2021), as well monogastric animals (Dörper et al., 2021; Veldkamp and Vernooij, 2021). In recent years there have been many studies and developments in practices that aim to properly incorporate insects into food and feed production systems.

However, many aspects of insect mass rearing for consumption remain unclear due to its relatively short history (Berggren et al., 2019). In particular, knowledge gaps exist in practical insect rearing, as not enough is known about the life histories, physiologies and behaviour of commercially important insect species. The fitness of organisms is highly influenced by a variety of biotic factors mediated by intra- and interspecific relationships (e.g. Applebaum and Heifetz, 1999; Harvey et al., 2013; Joosten et al., 2020; Remmel et al., 2010; Stock et al., 2009) and abiotic 
factors such as moisture (Bekker et al., 2021; Holmes et al., 2013; Tomberlin et al., 2002), food quality and quantity (Nguyen et al., 2013) and temperature (Tomberlin et al., 2009). However, the details of such influences are not sufficiently known, depend strongly on the taxa, and the interactions of different environmental effects are often overlooked.

Larval density is an important biotic factor that has been reported to considerably affect the life histories, fitness, morphology, behaviour and physiology of insects and other animals (Fantinou et al., 2008; Kawecki and Stearns, 1993; Tammaru et al., 2000). Crowding, in general, influences the body size and development time of insects and often leads to an increase in larval mortality (Applebaum and Heifetz, 1999; Pener and Simpson, 2009). From a commercial point of view, reducing body size at economically important life stages, coupled with an increase in development time, tends to be undesirable and costly. However, the opposite would be very welcome in commercial insect production as this would cut costs and bring in more significant profits to a still-emerging sector. For example, low larval density in insect mass rearing has been associated with higher amounts of crude fat (Barragán-Fonseca et al., 2018). Crude fat from insects has been reported in numerous studies to have high potential for use in the production of biofuel (Su et al., 2019; Wang et al., 2017; Wong et al., 2019;). In contrast, high larval density could result in intraspecific competition (Agnew et al., 2000; Schrader et al., 2015) or attract natural enemies (Anderson and May, 1981; Wilson, 2002; Wilson and Cotter, 2009). To mitigate these risks, insects are expected, and have been shown, to alter their life histories in response to changing conspecific densities. In particular, in several insect species, crowded larvae tend to mature earlier and at a smaller size (e.g. Esperk et al., 2007; Fantinou et al., 2008; Tammaru et al., 2000; Than et al., 2020; Vellau and Tammaru, 2012), which contradicts the general principle of a negative environmental correlation between size and age at maturity (Teder et al., 2014). Larvae grown at high densities are more likely to experience food shortages than those reared at low densities. However, in many studies the effects of larval density and food shortage could not be separated (Fantinou et al., 2008; Flockhart et al., 2012; Gibbs et al., 2004; Tammaru et al., 2000).

Temperature is one of the most important abiotic factors greatly influencing the fitness of all organisms and life histories of ectothermic animals such as insects (Angiletta et al., 2004; Atkinson and Sibly, 1997; Berger et al., 2012; Kingsolver and Huey, 2008). Thermal effects, both short(thermal shock) and long-lasting (increased averages), have received particular attention in recent years due to ongoing climate warming (Malhi et al., 2020; Skendžić et al., 2021). However, besides the direct effects on organisms, temperature is also known to modify the impact of other environmental factors such as humidity (Issimov et al.,
2021; Marr et al., 2019), food availability (Matiu et al., 2017; Sehgal et al., 2017; Venancio et al., 2020) and food quality (Jiang et al., 2018; Jonsson et al., 2013; Kilara and Sharkasi, 1986). Nevertheless, studies investigating the interactive effects of temperature and larval density are relatively rare and taxonomically biased (Couret et al., 2014; Ezeakacha and Yee, 2019; Reigada and Godoy, 2006; Zapletal et al., 2018).

Density effects on organismal traits are clearly understudied and prone to several methodological problems. Therefore, further studies using more advanced methodologies and focussing on organisms other than traditional model species are urgently needed. Recent research on commercially important insects has primarily focussed on bioconversion of waste products and food-quality influence on body mass, developmental time and body composition (Diener et al., 2009, 2011; Nguyen et al., 2013; Oonincx et al., 2015). However, rearing density influence on life-history traits, an effect of utmost importance in mass production, has received much less attention. The results of the density experiments are frequently conflicting, and studies are often methodologically limited. For example, although mortality is often positively correlated with larval density, the larval densities are not monitored during the study and dead larvae are not replaced. This often leads to a situation where the larval densities at the end of an experiment do not correspond to the beginning of the study. It is also important to note that temperature may modify the density effects considerably, with significant consequences to the life histories and fitness of organisms. In particular, temperature and density interactions have significantly influenced survival, development time, juvenile mortality, fitness, emergence rate and body size (Couret et al., 2014; Mamai et al., 2018; Nardoni Laws and Belovsky, 2010). However, respective studies focusing on edible insects are lacking. Therefore, knowledge of this interaction is needed for insect-mass production purposes.

The black soldier fly (Hermetia illucens; BSF hereafter) is a dipteran native to North and South America but has become widespread in tropical and subtropical regions worldwide (Sheppard et al., 1994). BSF larvae tend to aggregate voluntarily (Shishkov and Hu, 2020; Shishkov et al., 2019) - a trait it shares with other dipterans such as houseflies and blowflies (Rivers and Dahlem, 2013). Due to its polyphagous nature, the BSF holds a significant advantage as a waste recycler compared to other insects and is currently considered as one of the most promising insect species in producing food and feed (Bulak et al., 2018; Cammack and Tomberlin, 2017; Nguyen et al., 2013; Tomberlin and Van Huis, 2020; Tomberlin et al., 2002). The species is used to recycle organic waste and turn it into high-quality animal feed for monogastric domestic animals such as pigs, chickens and fish (Barragan-Fonseca et al., 2017). 
High larval densities in the BSF are previously shown to result in lower prepupal and pupal masses (BarraganFonseca et al., 2018; Jones and Tomberlin, 2019). Larval developmental time has been demonstrated to decrease in response to high conspecific densities in several insect species (Bauerfeind et al., 2005; Esperk et al., 2007; Lyimo et al., 1992; Vellau and Tammaru, 2012), but is reported to show the opposite pattern (longer at high densities) in the BSF (Jones and Tomberlin, 2019). In addition, previous larval density studies on the BSF suffer from methodological limitations that may hamper the interpretation of their results. In particular, rearing densities are typically estimated and confirmed only at the start of the experiment. This approach is problematic because larval survival is also frequently notably impacted by rearing density. Therefore, larval densities during investigations are likely to differ from the densities at the beginning of the experiment. For example, in ordinary situations, when rearing densities are negatively associated with larval survival (Jones and Tomberlin, 2019; this study), larval density in high-density treatments may be much lower than expected, especially during the late larval period. Additionally, all previous BSF density experiments (except for Jones and Tomberlin, 2019) measured different traits from different subsamples and did not discriminate between the sexes. Both of these subtleties could have had an impact on the results. The effect of temperature on BSF larvae has been reported to significantly influence larval development time, as well as larval wet mass (Chia et al., 2018; Harnden and Tomberlin, 2016). Other studies have reported that higher temperatures increase food intake, growth rate (Gligorescu et al., 2018) and increase mortality (Raimondi et al., 2020) in BSF larvae. However, larval density and temperature interactions have not yet been studied in this species. Knowledge on the interaction of these two factors would help estimate optimal responses and properly optimise mass production systems.

Using methodologies that aim to overcome the shortcomings of previous studies, we investigate larval density effects, temperature effects and density-temperature interactions on life-history traits of a commercially important BSF. Specifically, we reared BSF larvae at three different larval densities at three temperature regimes. We measured mass at the prepupal, pupal, and adult stage; duration of the larval, pupal and adult period; survival in the early and late larval period; and fat content in the prepupal stage. Food was provided in surplus so that even at the highest larval density, larvae never experienced starvation. As a methodological addition, we evaluated rearing densities in replicates from all treatments by re-counting the larvae approximately in the middle of their development and replaced the dead larvae to restore the desired larval densities. To further mitigate potential methodological issues, we took an individual-based approach, determined the sexes of the individuals, and included an additional environmental factor (temperature) in the design to test for possible interactions with rearing density. As a novel approach for BSF we also studied temperature and larval density interactions.

\section{Materials and methods}

\section{Fly culture}

Eggs of the BSF were obtained from an already existing colony at the University of Tartu, Estonia. The BSF colony was established in 2017 from around 500 female flies originating from a laboratory culture in the United Kingdom. Adult BSFs were kept in a hand-constructed breeding cage with the dimensions $130 \mathrm{~cm}$ (length) $\times 130$ $\mathrm{cm}$ (width) $\times 150 \mathrm{~cm}$ (height), which housed approximately 3,000 flies and was maintained at $26 \pm 3{ }^{\circ} \mathrm{C}$ and $40 \pm 5 \%$ relative humidity. Adult BSFs were provided with drinking water daily, which was administered by sprinkling it on the cage walls. Only eggs oviposited by the females within 24 hours before the experiment were collected. This was to ensure that the development of larvae was synchronised at the beginning of the experiment. On the day eggs were collected, they were transferred into a polypropylene container $15 \mathrm{~cm}$ (length) $\times 15 \mathrm{~cm}$ (width) $\times 20 \mathrm{~cm}$ (height) filled with dog food pellets ( $60 \%$ moisture) that had become a soft mush. The main ingredients for the dog food pellet $\left(\right.$ Barker $\left.^{\mathrm{rn}}\right)$ were cereals, meat and animal derivatives. Dog food pellets were chosen as the food source because of their nutritional uniformity and lower risk of developing mould than the classically used chicken feed (personal observations of the authors). The dog food pellets had the following nutritional values crude protein: $22 \%$, crude oils and fats: $8 \%$, crude ash: $8.5 \%$, crude fibres: $4 \%$, omega 3 : $0.12 \%$, omega 6: $1.48 \%$.

\section{Experimental design}

BSF larvae were reared from egg to pupation in controlled conditions using a common garden setting, i.e. crossed experimental design of density and temperature treatments. Six-day-old larvae were placed in transparent polypropylene containers of $30 \mathrm{~cm}$ (height) $\times 10.46 \mathrm{~cm}$ (diameter) with a base area of $86 \mathrm{~cm}^{2}$ containing $40 \mathrm{~g}$ of soaked dog food pellets (60\% moisture). The larvae were reared in a single container up to this point. In particular, three density treatments were created: 86, 420 and 860 larvae per container (hand-counted with the aid of a brush to avoid damage to larvae), which represented treatments of 1 larvae $/ \mathrm{cm}^{2}$ (low density), 5 larvae $/ \mathrm{cm}^{2}$ (medium density) and 10 larvae $/ \mathrm{cm}^{2}$ (high density), respectively. Larvae were reared until pupation using a randomised design in three climate-control chambers, each programmed to a different temperature $\left(23{ }^{\circ} \mathrm{C}\right.$ (low temperature), $27{ }^{\circ} \mathrm{C}$ (medium temperature) and $30{ }^{\circ} \mathrm{C}$ (high temperature)), $60 \%$ relative humidity with a photoperiod regime of $12: 12$ (L:D) hours. The local temperature was also monitored 
daily within all containers, but because of low variation in general and absence of systematic thermal differences between the density treatments (Table S1), this data was not considered in further analyses. There were 15 containers in each climate-control chamber representing five replicates of each larval density treatment; the position of the containers was randomised within the chambers. Larvae were fed every other day, and food was provided ad libitum (amount determined as described by Barragan-Fonseca et al. (2018)) so that larvae in the high-density treatment never experienced starvation. The food in each container was stirred daily to allow for proper aeration and to ensure the same quantity of food throughout the container. The inclusion of the maintenance replicate was to aid in the replacement of larvae that experienced mortality during the first half of the larval period to keep the density of the treatments the same after the determination of survival rate. All plastic containers were covered with a mesh cloth and fastened with a rubber band to regulate the microclimate within containers.

\section{Determination of life-history traits}

Survival rate was evaluated for the first time at the midpoint of the experiments, when most of the larvae in the replicate had moulted into their $4^{\text {th }}$ instar (determined as described by Kim et al. (2010)), and for the second time after $70 \%$ of the larvae had moulted into the prepupal stage, (determined as described by Tomberlin et al. (2002)). Survival rate was expressed as the percentage of larvae that survived from the beginning of the experiment until the beginning of the $4^{\text {th }}$ larval instar and from the $4^{\text {th }}$ larval instar until prepupation. Only individuals from the corresponding density and temperature treatments' maintenance replicate were added to the containers after survival rate estimation at the $4^{\text {th }}$ larval instar. Body mass, and not body length, was used as a measure of size throughout the study as the latter could often not be measured in a reliable way in immature insects, and mass and length are shown to be highly correlated in the BSF (Harnden and Tomberlin, 2016).

Larval development time was measured from the beginning of the $1^{\text {st }}$ larval instar (including 6 days after hatching, when all larvae were kept in a common environment) until the observation of the first prepupa. Larvae were observed daily, and development time was estimated at the point where approximately $40 \%$ of the individuals of the replicate had been observed to have moulted into prepupae. After prepupation, sixty random prepupae from the replicates of each density treatment were taken to calculate prepupal mass. Individuals were washed with distilled water at room temperature and dried with a paper towel immediately before weighing individually. After weighing, the prepupae were placed separately in $7.5 \mathrm{~cm}$ (height) $\times 3 \mathrm{~cm}$ (diameter) transparent plastic vials covered with a perforated lid. To determine pupal development time, pupae (determined as described by Dzepe et al. (2020)) were then kept until adult eclosion at the same temperature regime at which they were kept in the larval stage. Duration of the pupal period was recorded as the time between pupation and adult eclosion. After pupation, the individuals were weighed again. The relative mass loss between the prepupal and pupal stage was measured by dividing the mass at the prepupal stage by the mass at the pupal stage.

Time (days) to adult emergence was recorded for each isolated pupa, and emerged adults were sexed. All eclosed adults were weighed on the second day after eclosion and transferred to a $27^{\circ} \mathrm{C}$ climate-control chamber to measure adult longevity. This temperature was chosen as the optimal temperature for the species based on the study by Tomberlin et al. (2009).

\section{Fat content}

Twenty-four prepupae were chosen at random from each replicate (and 72 for each density*temperature combination) on the first day after they moulted into prepupae. They were isolated and stored at $-80{ }^{\circ} \mathrm{C}$ until further analysis. The prepupae were weighed and then dried in an oven (MIR-162 oven, 5-5, Sanyo Electric Co. Ltd., Osaka, Japan) for $72 \mathrm{~h}$ at $60{ }^{\circ} \mathrm{C}$. Relative fat content was determined using a CEM Rapid NMR Fat Analyzer (CEM Corporation, Matthews, NC, USA). All fat content measurements were performed in triplicate, and the mean of the three measurements was used in statistical analyses.

\section{Statistical analysis}

Larval survival rate was analysed using generalised linear mixed models (GLMMs); all other life-history traits were analysed using linear mixed models (LMMs). Container was included as a random effect to account for possible microclimatic differences (such as variation in substrate viscosity and local temperature) in replicate containers in both life-history and fat analysis; denominator degrees of freedom were estimated using the Satterthwaite method (Satterthwaite, 1946). The effect of sex on fat content was not included because sexing of prepupae is not feasible in this species. Definitive models were constructed by sequentially removing non-significant interaction terms. Tukey's HSD (Honest significance difference) tests were used for post hoc contrasts for separation of means. The R packages emmeans (Searle et al., 1980), lme4 (Bates et al., 2015) and lmerTest (Kuznetsova et al., 2017) were used to build the models for all life-history traits, as well as larval survival rate. The R package pbkrtest (Halekoh and Højsgaard, 2014) was used to extract p-values from the binomial models built for estimating larval survival rate. All statistical analyses were performed using $R$ version 4.0.3 (R Core Team, 2020). 


\section{Results}

\section{Larval survival rate}

Larval survival rate was significantly different among all density treatments, both for the period from the start of the experiment until the beginning of the $4^{\text {th }}$ larval instar and after the $4^{\text {th }}$ larval instar until the prepupal stage (Figure 1, Table 1). In particular, larvae reared at the low-density treatment had significantly higher survival (on average $10 \%$ higher from the start of experiment until the start of $4^{\text {th }}$ larval instar and $11 \%$ higher after $4^{\text {th }}$ larval instar until prepupation) than those reared at medium density (Table 1, Figure 1). Survival differences between low- and high-density treatments were even more pronounced, being $20 \%$ higher from the start of the experiment until the beginning of the $4^{\text {th }}$ larval instar and $26 \%$ higher after the $4^{\text {th }}$ larval instar until prepupation in low than in highdensity treatment. Individuals reared at medium density had a $10 \%$ higher survival from the start of the experiment until the beginning of the $4^{\text {th }}$ larval instar and $16 \%$ higher survival after the $4^{\text {th }}$ larval instar until prepupation than those kept at high density (both differences significant; Table 1, Figure 1). Temperature did not significantly affect survival, but survival tended to be lower in the high-temperature treatment (Table 1, Figure 1).

\section{Body size}

Larval density significantly affected prepupal mass (Table 2). In particular, individuals reared at low density achieved significantly higher prepupal mass than those kept at medium density (17\% higher, on average) and high density (38\% higher at low density) (Table 2, Figure 2). Individuals reared at medium density also achieved significantly higher prepupal masses (15\%, on average) than those kept at high density. Temperature significantly affected prepupal mass (Table 2), as higher prepupal mass was mostly achieved at a low rather than medium or high temperature (Figure 2). However, the effect of temperature was dependent on the density and sex (significant interaction terms, Table 2). At medium density, male prepupae were lighter at low temperature than in other temperature treatments (Figure 2). Females in all density treatments were on average 6-14\% heavier than their male counterparts (significant differences; Table 2, Figure 2).

Larval density had a significant impact on pupal mass (Table 3). Individuals reared at low density achieved significantly higher pupal masses than those kept at medium density (20\% higher at low density, on average) or high density $(24 \%$ higher at low density) (Table 3, Figure 3). Temperature had a significant effect on pupal mass (Table 3), with a higher pupal mass achieved at high and medium temperatures than at a low temperature (Figure 3). However, the effect of temperature was dependent on density and sex (significant interaction terms, Table 3), so that female pupae at low and medium densities and male pupae at a low density were lighter at a low temperature than in other temperature treatments; however, there were no significant differences in other density treatment and sex combinations (Figure 3). Female pupae in all density treatments were on average 1-4\% larger than their male counterparts (significant differences; Table 3, Figure 3).

The mass loss in the prepupal stage was significantly dependent on larval density (Table 4), with individuals at a high density tending to lose less mass than those from low and medium densities (Figure 4). However, this effect was strongly dependent on temperature and sex (significant interaction terms; Table 4). Individuals reared at low temperature lost more mass than those kept at medium or high temperatures, with males at medium density being the only exception (Table 4, Figure 4). Females lost more mass than males (Table 4, Figure 4), but the difference was smaller in the low-density treatment than in medium- and high-density treatments (Figure 4).

Larval density significantly influenced adult mass (Table 5). In particular, individuals that experienced low rearing density in their larval stage achieved significantly higher (35\%, on average) adult mass than those from medium- and high-density treatments, and adult mass in the mediumlarval-density treatment was higher $(12 \%$, on average) than in the high-density treatment (Table 5, Figure 5). Adult mass was lower in the low-temperature treatment than in the medium- and high-temperature treatments, with the difference between the low-temperature treatment and other thermal treatments being highest at medium larval density (Table 5, Figure 5). Sex only had a marginally nonsignificant effect on adult mass (Table 5, Figure 5).

\section{Duration of life stages}

Larval development time (including 6 days after hatching, which all larvae spent in a common environment) was significantly shorter (22-28\%, on average) at low larval density than in other density treatments (Table 6, Figure 6), while larval periods in medium- and high-density treatments did not differ significantly from each other (Figure 6). The larval period was longer (4-10\%, on average) at a low temperature than in medium- and high-temperature treatments (Table 6, Figure 6). Males had 8\% shorter larval development times than females, the difference being larger at a low temperature than at medium and high temperatures (Table 6, Figure 6). Temperature modified the effects of density and sex (significant interaction terms, Table 6), as higher differences between the low-temperature treatment and other thermal treatments appeared at medium density, and the difference between thermal treatments was higher in females than in males. 

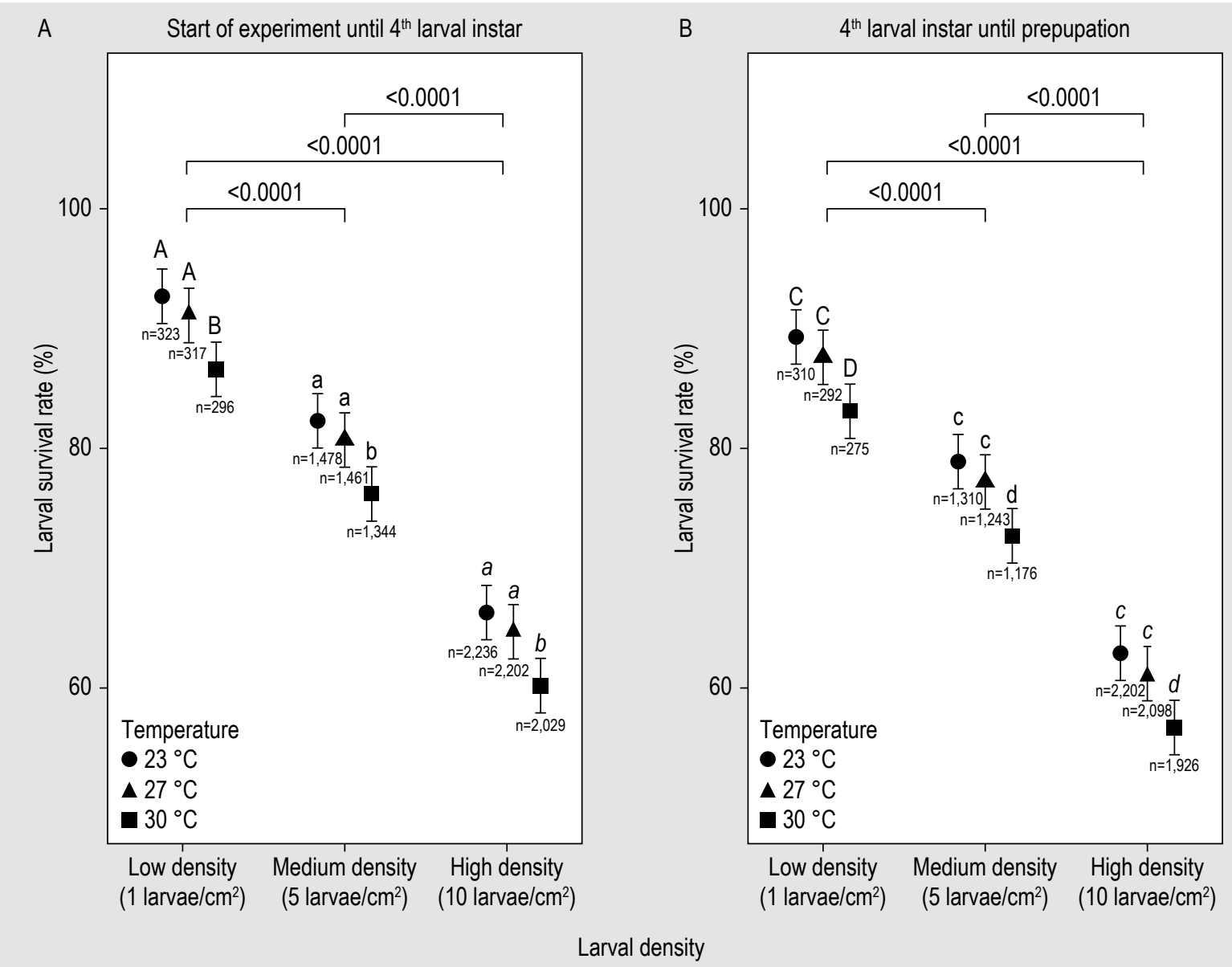

Figure 1. Larval survival from the start of the experiment until the beginning of the $4^{\text {th }}$ larval instar (A) and from the $4^{\text {th }}$ larval instar until the prepupal stage (B) of black soldier fly larvae. Estimated marginal means were estimated using $R$ version 4.0.3, package emmeans (Searle et al., 1980). Estimated marginal means at the same larval density followed by the same lowercase, uppercase or italic letters are not significantly different $(P>0.05)$. A generalised linear model followed by a Tukey's honest significant difference test was used. ' $n$ ' marks sample sizes of all density $\times$ temperature combinations (survived and dead individuals pooled). Error bars indicate standard error.

Table 1. Results of the generalised linear mixed model related to the effects of larval density on the larval survival rate of the BSF from the start of the experiment until the beginning of the $4^{\text {th }}$ larval instar and from the $4^{\text {th }}$ larval instar until the prepupal stage of black soldier fly larvae. The container was included as a random effect to account for microclimatic differences.

\begin{tabular}{lllll} 
& \multicolumn{2}{c}{ Start of experiment until $4^{\text {th }}$ larval instar } & & $4^{\text {th }}$ larval instar until prepupation \\
\cline { 2 - 3 } Trait & df & $P$ & df & \\
Larval density & 2 & $<0.0001$ & 2 & $<0.0001$ \\
Temperature & 2 & 0.3009 & 2 & 0.5757 \\
\hline
\end{tabular}

${ }^{1}$ Survival was higher in the low-density treatment compared to other density treatments and higher in the medium-density treatment compared to the high-density treatment. 


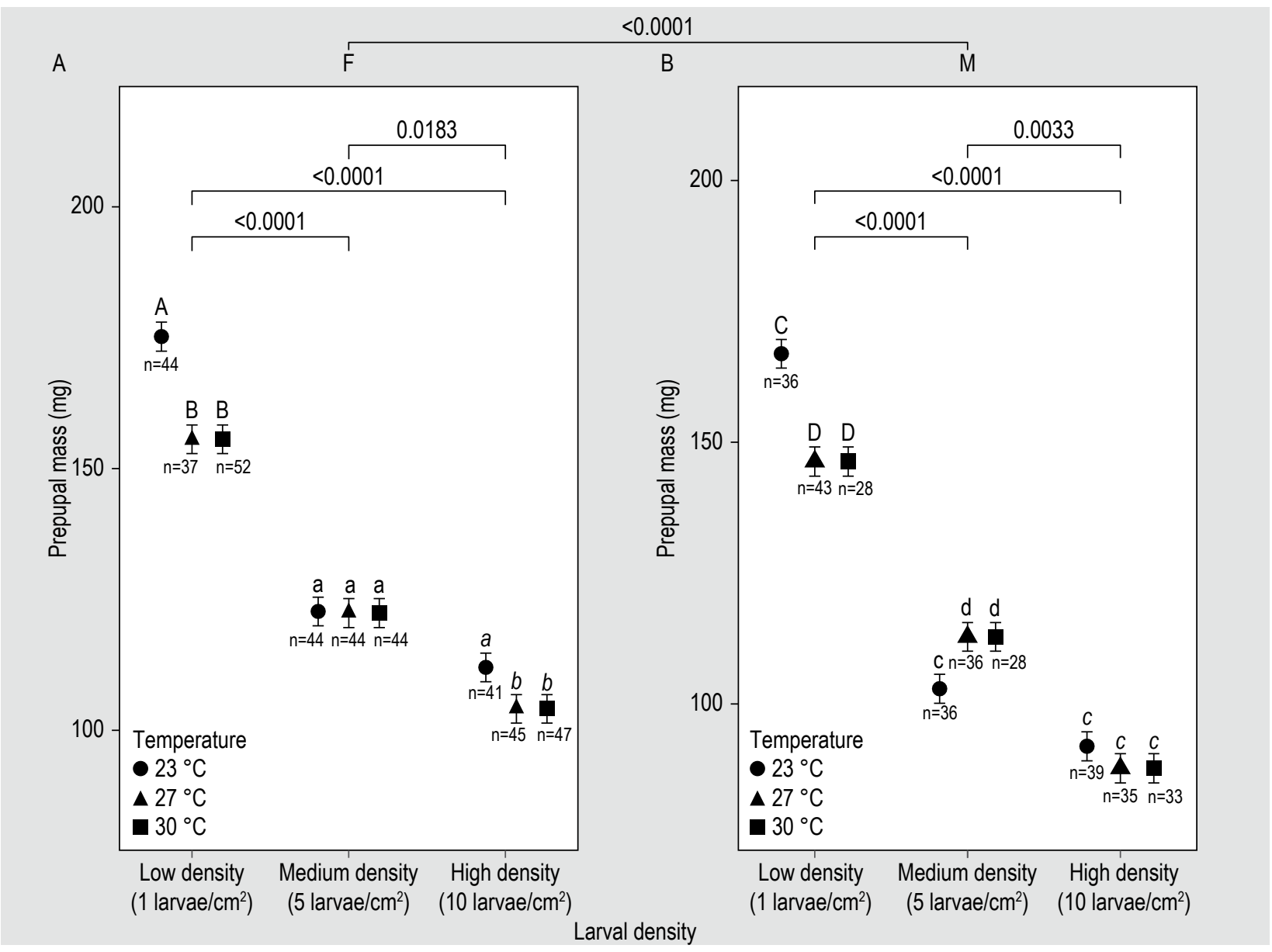

Figure 2. Prepupal mass of the black soldier fly. For density treatment comparisons, all temperatures were pooled and temperature comparisons were made separately for all density treatments. 'F' and 'M' denote females and males, respectively. See Figure 1 for details. ' $n$ ' marks sample sizes of measured larvae.

Table 2. Results of the linear mixed model related to the effects of larval density, temperature and sex on the prepupal mass of the black soldier fly. Container was included as a random effect to account for microclimatic differences. ${ }^{1}$

\begin{tabular}{|c|c|c|c|}
\hline Trait & df & $\mathbf{F}$ & $P$ \\
\hline Larval density ${ }^{2}$ & 2,9 & 136.8 & $<0.0001$ \\
\hline Temperature $^{3}$ & 2,693 & 117.6 & $<0.0001$ \\
\hline Sex & 1,696 & 817.3 & $<0.0001$ \\
\hline Larval density $\times$ Temperature ${ }^{5}$ & 4,693 & 121.6 & $<0.0001$ \\
\hline Larval density $\times \operatorname{Sex}^{6}$ & 2,696 & 28.7 & $<0.0001$ \\
\hline TemperaturexSex ${ }^{7}$ & 2,694 & 10.4 & $<0.0001$ \\
\hline Larval density $\times$ Sex $\times$ Temperature ${ }^{8}$ & 4,694 & 5.8 & 0.000 \\
\hline
\end{tabular}

\footnotetext{
${ }^{1}$ Individuals included in the analysis were those that survived until eclosion. Degrees of freedom were estimated by the Satterthwaite method. Full models were simplified so that only interactions statistically significant at the 0.05 level are included.

${ }^{2}$ Prepupal mass was heavier in the low-larval-density treatment compared to other density treatments and heavier in the medium- than in the high-larval-density treatment.

${ }^{3}$ Prepupal mass was heavier at a low temperature compared to other temperature treatments.

${ }^{4}$ Females had heavier prepupal mass than males.

${ }^{5}$ At low and high densities, prepupal mass was higher in the low-temperature treatment, while such a pattern was not observed at medium density.

${ }^{6}$ Higher differences in prepupal mass between density treatments in males than in females.

${ }^{7}$ Prepupal mass was heavier at a low than at a medium or high temperature in females.

${ }^{8}$ At medium density, prepupal mass of males was higher in medium- and high-temperature treatments than in the low-temperature treatment.
} 


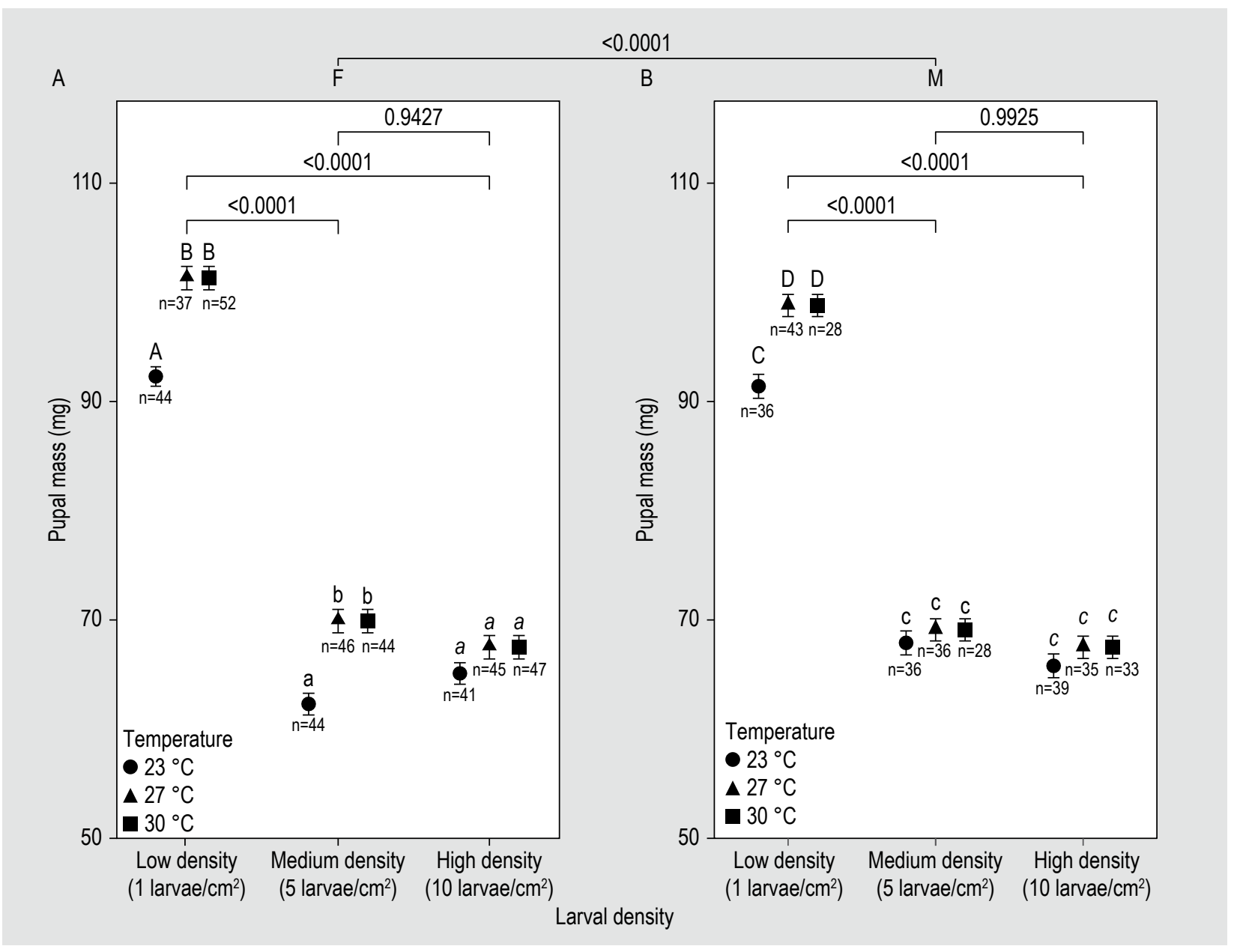

Figure 3. Pupal mass of the black soldier fly. See Figures 1 and 2 for details.

Table 3. Results of the linear mixed model related to the effects of larval density, temperature and sex on pupal mass of the black soldier fly. See Table 2 for details.

\begin{tabular}{llrr} 
Trait & df & F & P \\
& & & $<0.0001$ \\
Larval density $^{1}$ & 2,9 & 343.0 & $<0.0001$ \\
Temperature $^{2}$ & 2,693 & 56.1 & $<0.0001$ \\
Sex $^{3}$ & 1,700 & 26.8 & 0.0002 \\
Larval densityxTemperature $^{4}$ & 4,693 & 5.5 & 0.0045 \\
Larval densityxSexxTemperature $^{5}$ & 4,697 & 3.8 & \\
\hline
\end{tabular}

${ }^{1}$ Pupal mass was higher in the low-larval-density treatment compared to other larval-density treatments.

2 Pupal mass was higher at medium and high temperatures than at a low temperature.

${ }^{3}$ Females had higher pupal mass than males.

${ }^{4}$ Pupal mass differences between temperature treatments were higher at low and medium densities compared to the high-density treatment.

${ }^{5}$ No significant differences in pupal mass between the low temperature treatment and other temperature treatments at medium density in males. 


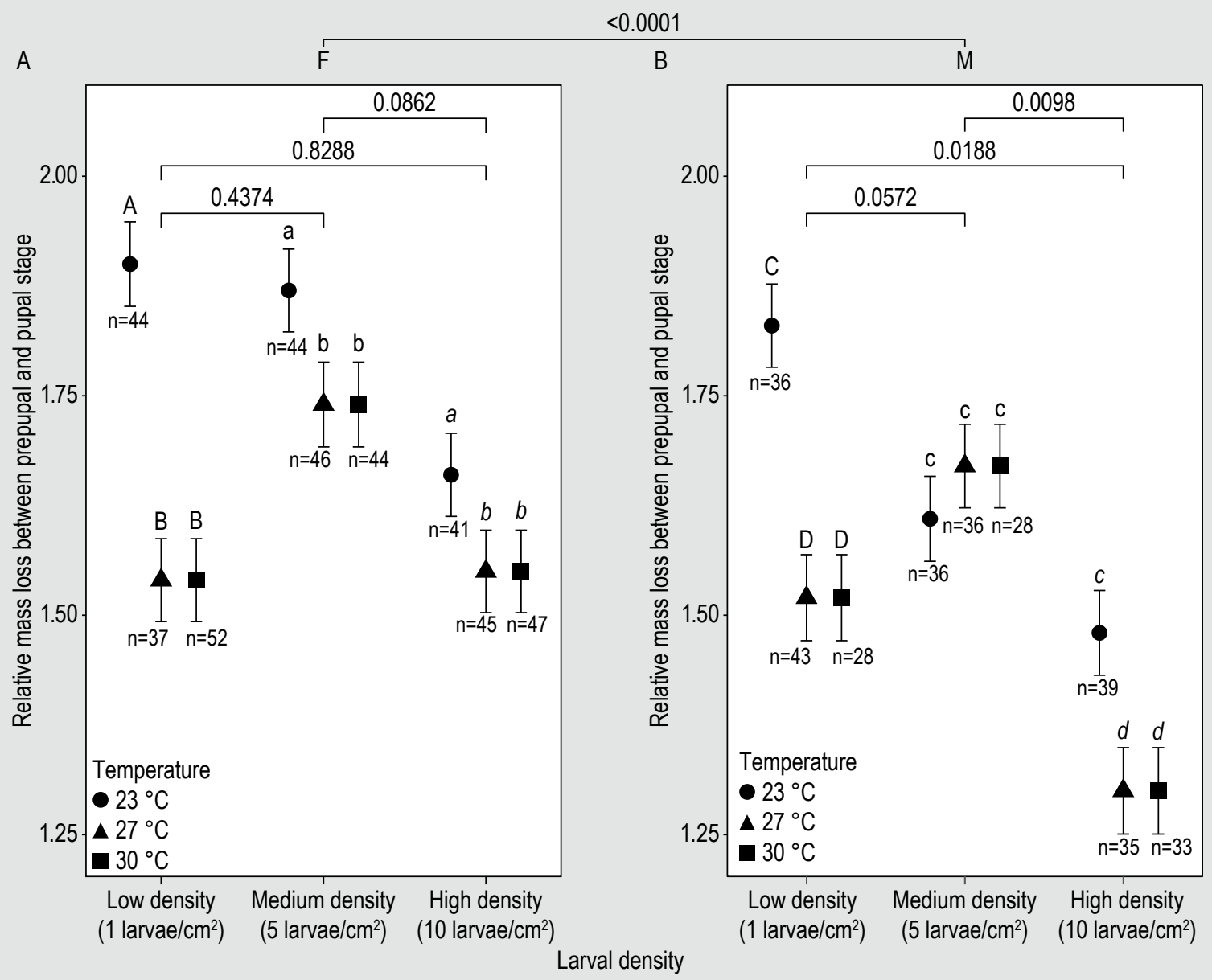

Figure 4. Mass loss between prepupal and pupal stage of black soldier fly larvae. Mass loss was calculated as prepupal mass divided by pupal mass. See Figures 1 and 2 for details.

Table 4. Results of the linear mixed model related to the effects of larval density, temperature and sex on mass loss between the prepupal and pupal stage of the black soldier fly. Mass loss was calculated as prepupal mass divided by pupal mass. See Table 2 for details.

Trait

Larval density $^{1}$

Temperature ${ }^{2}$

Sex ${ }^{3}$

Larval density $x$ Temperature ${ }^{4}$

Larval density $\times \operatorname{Sex}^{5}$

Temperature $\times \operatorname{Sex}^{6}$

Larval density $\times$ Temperature $\times \operatorname{Sex}^{7}$ df

2,9

2,693

1,698

4,693

2,698

2,694

4,694
F

$\begin{array}{rr}8.1 & 0.0097 \\ 127.6 & <0.0001 \\ 154.6 & <0.0001 \\ 31.5 & <0.0001 \\ 24.3 & <0.0001 \\ 4.1 & 0.0174 \\ 5.8 & 0.0001\end{array}$

${ }^{1}$ Higher mass loss in low- and medium-density treatments compared to the high-density treatment.

${ }^{2}$ Higher mass loss at a low temperature compared to other temperature treatments.

${ }^{3}$ Higher mass loss in females than in males.

${ }^{4}$ Differences in mass loss between temperature treatments was higher at low density than in other density treatments.

${ }^{5}$ Differences between mass loss in density treatments was higher in males than in females.

${ }^{6}$ Differences between mass loss in the low-temperature treatment and other temperature treatments was higher in females than in males.

${ }^{7}$ No difference in mass loss between the low-temperature and other temperature treatments in males at medium density. 


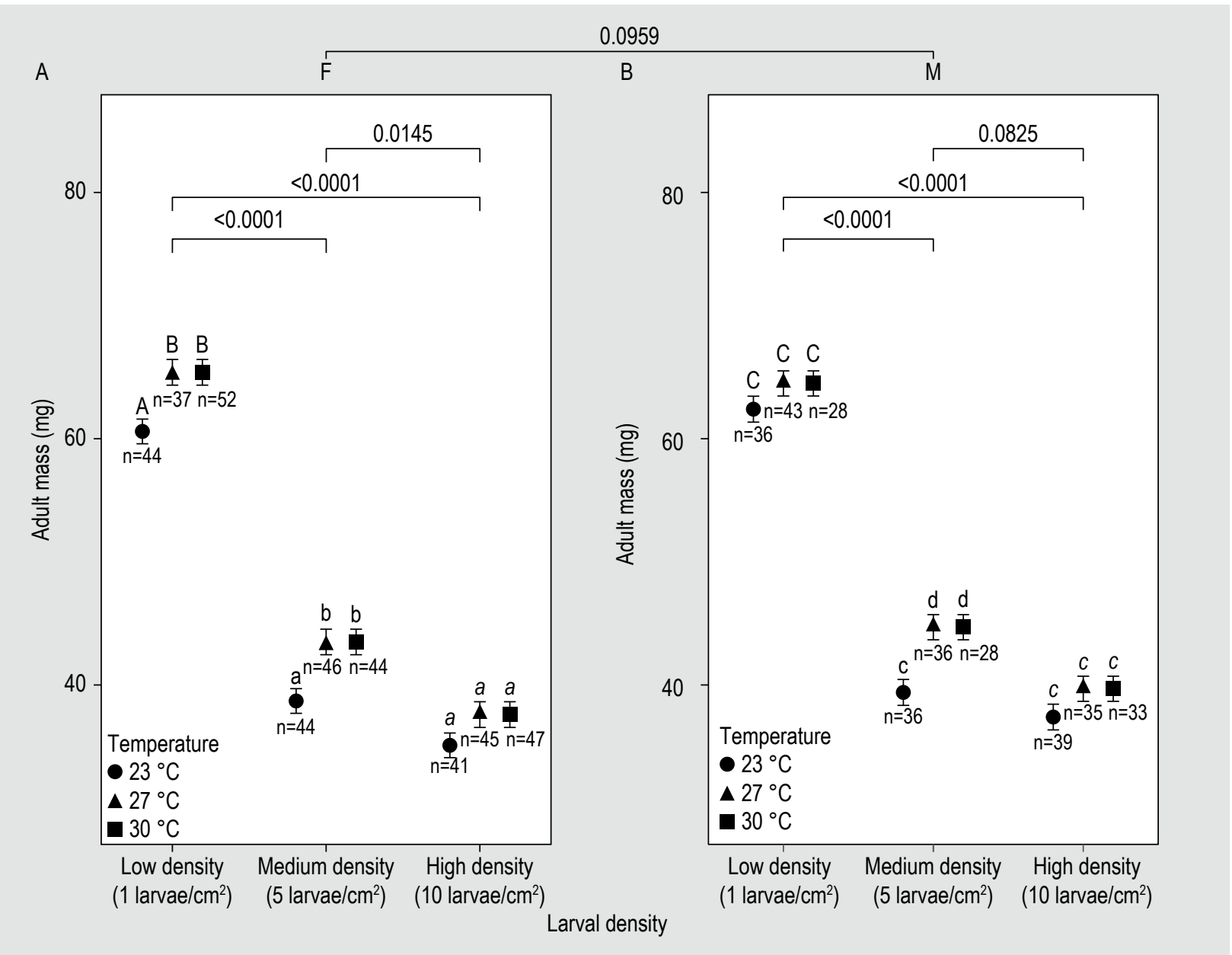

Figure 5. Adult mass of black soldier fly. See Figures 1 and 2 for details..

Table 5. Results of the linear mixed model related to the effects of larval density, temperature and sex on adult mass of the black soldier fly. See Table 2 for details.

$\begin{array}{llrr}\text { Trait } & \text { df } & \text { F } & \text { P } \\ & & & <0.0001 \\ \text { Larval density }^{1} & 2,9 & 4,722.5 & <0.0001 \\ \text { Temperature }^{2} & 2,693 & 6.9 & 0.0959 \\ \text { Sex } & 1,700 & 2.7 & 0.0049 \\ \text { Larval densityxTemperature }^{3} & 4,693 & 3.4 & 0.0017 \\ \text { Larval densityxSex }^{4} & 2,700 & 6.5 & \end{array}$

${ }^{1}$ Adult mass was higher in the low-density treatment compared to other density treatments and heavier in the medium-density treatment compared to the highdensity treatment.

${ }^{2}$ Adult mass was higher at medium and high temperatures than at a low temperature during the larval stage.

${ }^{3}$ Adult mass differences between the low-temperature treatment and other temperature treatments were higher at medium density.

${ }^{4}$ Higher differences in adult mass between density treatments in females than in males. 


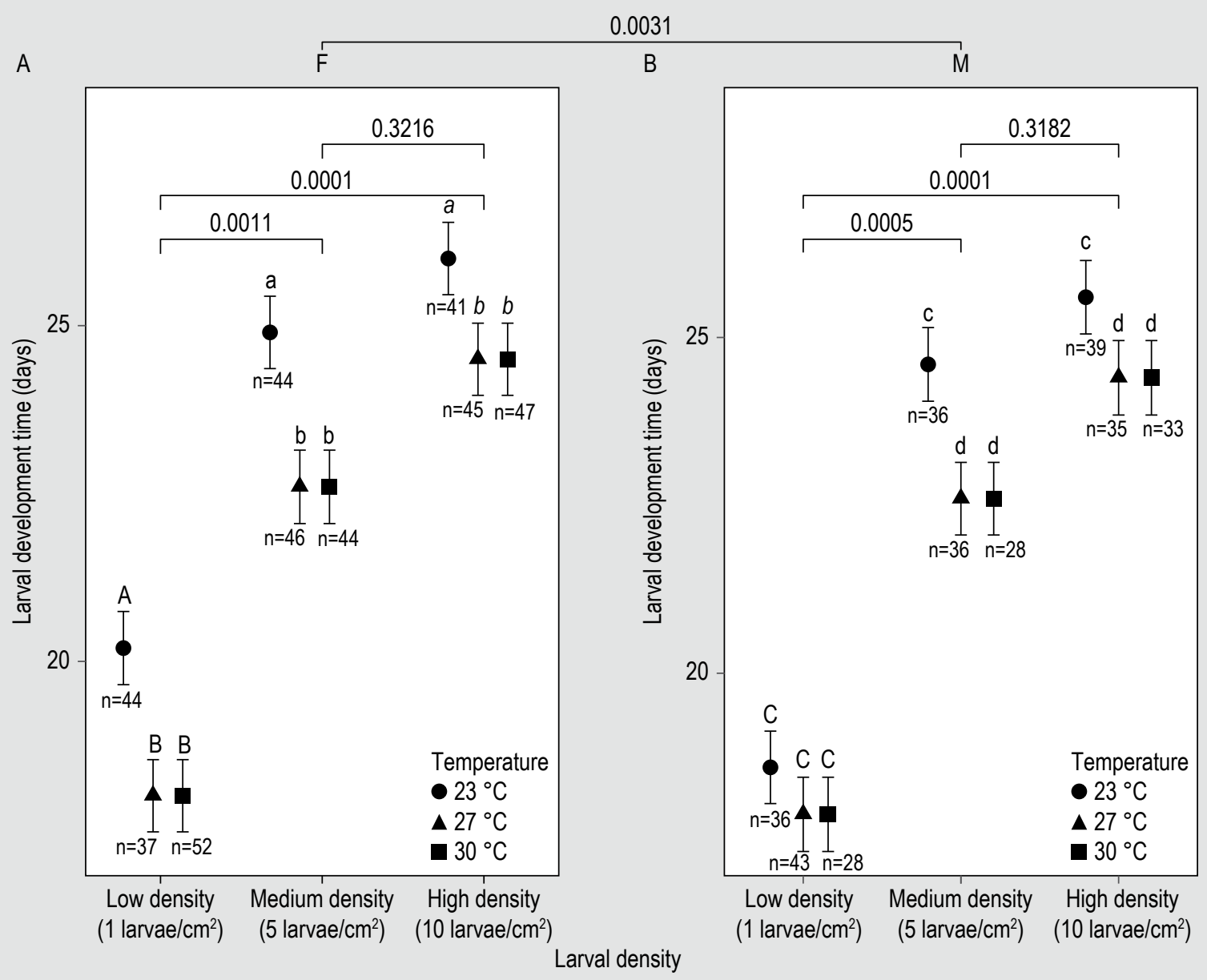

Figure 6. Larval development time of the black soldier fly. See Figures 1 and 2 for details.

Table 6. Results of the linear mixed model related to the effects of larval density, temperature and sex on larval development time (measured as the period between the start of the experiment at $1^{\text {st }}$ larval instar until prepupation) of black soldier fly larvae. See Table 2 for details.

Effect

Larval density $^{1}$

Temperature ${ }^{2}$

Sex $^{3}$

Larval density $\times$ Temperature ${ }^{4}$

Temperature $\times \mathrm{Sex}^{5}$ df

2,9

2,693

1,697

4,693

2,694
$\mathbf{F}$

43.3

135.7

8.8

3.0

4.9
$P$

$<0.0001$

$<0.0001$

0.0031

0.0173

0.0081

${ }^{1}$ Shorter larval period in the low-density treatment than in other density treatments.

${ }^{2}$ Shorter larval period in the high-temperature and medium-temperature treatments compared to the low-temperature treatment.

3 Shorter larval period in males than in females.

${ }^{4}$ Greater differences in larval period between the low-temperature treatment and other temperature treatments at medium density.

${ }^{5}$ Larval period difference between temperature treatments was greater in females than in males. 
Pupal development time was significantly (4-6\%) shorter at low larval density than in other density treatments (Table 7, Figure 7). Temperature had a significant effect on pupal development time (Table 7). Namely, at a low temperature, the pupal period was longer ( $9 \%$, on average) than in other temperature treatments, but the difference was influenced by sex (Table 7, Figure 7). The pupal period was shorter for males than for females ( 7 vs 8.5 days, respectively; Table 7, Figure 7).

Individuals reared at low larval density had longer adult period (33\%, i.e. 1-1.9 days longer, on average) than those kept at medium or high larval density (Table 8, Figure 8). Temperature during the larval and pupal stage did not have a significant overall effect on adult longevity (Table 8). However, a significant interaction between larval density and temperature (Table 8 ) indicates that in the medium-density treatment, adult period was longer at a low temperature than at medium and high temperatures, while the relationship was reversed in the low- and high-density treatments (Figure 8). Male adults lived, on average, 7 days (15\%) longer than females (Table 8, Figure 8).

\section{Fat content}

Fat content of prepupae from the low-larval-density treatment was higher (18-26\%, on average) than that of the medium- and low-density treatments, and prepupae from the medium-density treatment had a higher fat content ( $12 \%$ higher, on average) than those from the highdensity treatment (Table 9, Figure 9). The density effect was influenced by temperature (significant interaction term, Table 9), so that at low density, larvae in the hightemperature treatment had a lower fat content than larvae from other thermal treatments, whereas at medium and high densities, larvae in the low-temperature treatment had a higher fat content than those from the other thermal treatments (Figure 9).

\section{Discussion}

This study provides insights into larval density and temperature effects on life-history traits by rearing larvae of a commercially important insect species (BSF) at three different densities and temperatures. A study like this is vital to ascertain the proper range for rearing densities in order to help optimise insect production, ultimately with the aim to apply this on an industrial scale. To reduce the methodological problems that perhaps inevitably challenge larval density studies, we used an improved, individualbased approach with a density control and replacement of the dead larvae in the middle of the larval period. To study the interactive effects of larval density on other environmental factors - an essential but often overlooked aspect in density studies - three temperature regimes were introduced to our methodological setting.
Our results demonstrate that high larval densities should be considered as a suboptimal environment for BSFs. This is because larval survival was higher, duration of larval period shorter, adult period longer, and prepupal mass, pupal mass, adult mass and fat content higher in a lowlarval-density treatment ( 1 larva $/ \mathrm{cm}^{2}$ ) compared to other density treatments. Consistently, in a medium-larvaldensity treatment (5 larvae/ $\mathrm{cm}^{2}$ ), survival, prepupal mass, adult mass and fat content was higher than in a high-larvaldensity treatment. There were also significant differences between density treatments in the duration of the pupal period and between medium- and high-density treatments in the duration of larval and pupal periods, adult longevity and pupal mass. Interestingly, a tendency for lower mass loss during the prepupal stage emerged at high rearing density, although thermal effects strongly influenced this. As expected, temperature significantly impacted the duration of the larval and pupal periods, prepupal mass, pupal mass, and adult body mass. However, the thermal effect was quite variable, and in seven out of ten traits studied, highly dependent on larval density, indicating strong interactions between these factors. It is also important to mention that body mass varied considerably despite larvae being approximately the same age. Prepupae, pupae and adults at all studied densities tended to be heavier at higher temperatures. Females achieved higher prepupal and pupal mass, but not higher adult mass than males. Females also lost more mass during the prepupal stage and had longer larval and pupal periods, but a shorter adult life than males.

Larval survival was negatively influenced by larval density both during the early and late larval periods. The studies by Barragan-Fonseca et al. (2018) and Jones and Tomberlin (2019) revealed that larval survival reduces as larval density increases in the BSF. However, the actual larval densities within high-density treatments inevitably decreased during these experiments, which likely impacts results substantially. To avoid this, we maintained constant larval densities in our study by substituting dead larvae at approximately the beginning of the $4^{\text {th }}$ larval instar (after most larvae in respective replicates had moulted to their $4^{\text {th }}$ larval instar).

A longer developmental period in suboptimal conditions is a widespread phenomenon in insects (Green et al., 2002; Oonincx et al., 2015; Tammaru et al., 2015; Teder et al., 2014). However, in the case of larval density, the opposite (shorter larval period at high densities) is expected and also shown in several insect species (Bauerfeind et al., 2005; Esperk et al., 2007; Lyimo et al., 1992; Tammaru et al., 2000; Vellau and Tammaru, 2012). This could be because larvae may reduce their developmental time in order to escape from undesirable situations. However, consistent with previous studies on the BSF (Barragan-Fonseca et al., 2018; Jones and Tomberlin, 2019), we observed that larvae reared at lower larval density had a notably shorter $(21 \%$ 


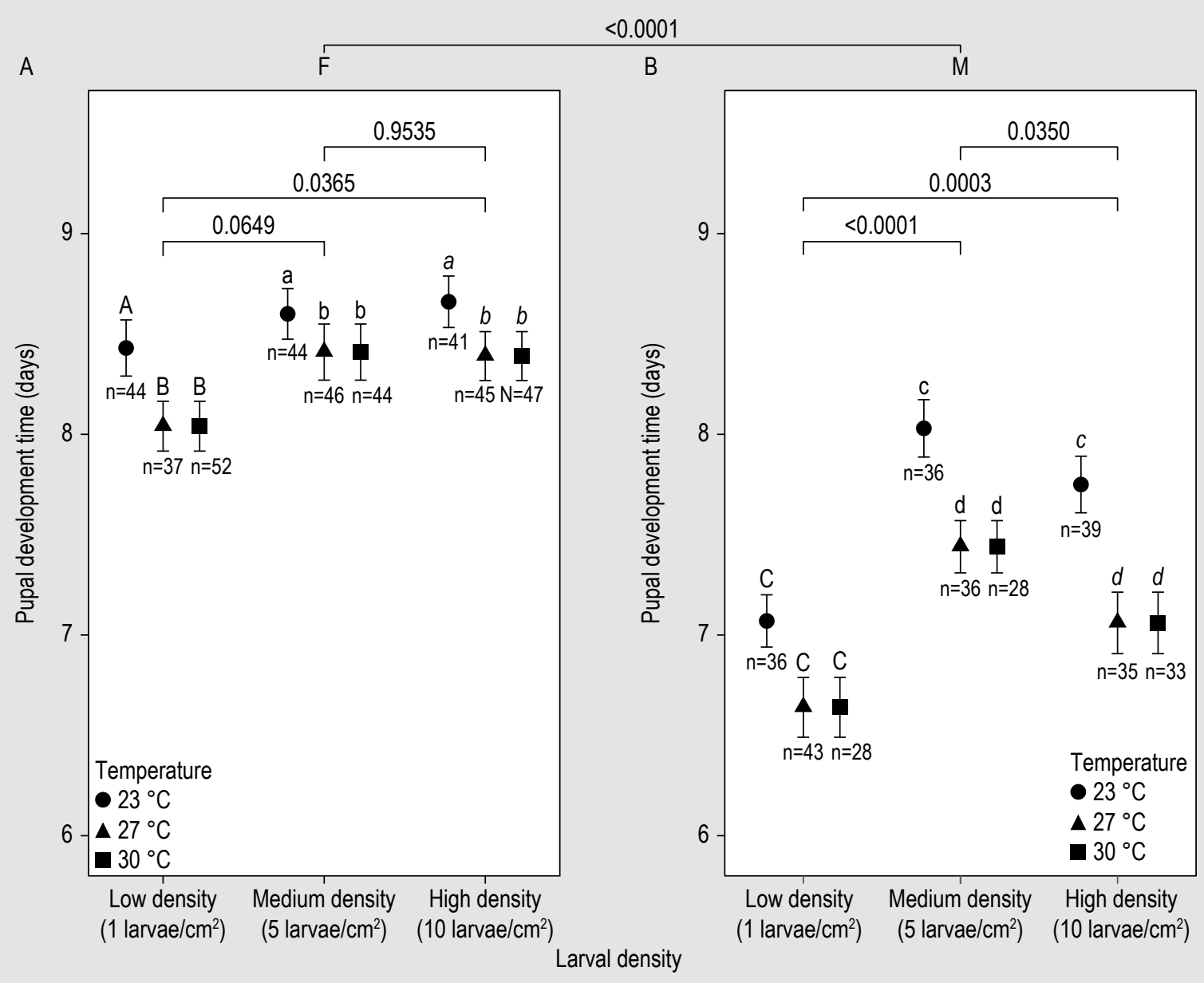

Figure 7. Pupal development time of the black soldier fly. Until pupation, each prepupa was kept in the same temperature treatment it was originally assigned to. See Figures 1 and 2 for details.

Table 7. Results of the linear mixed model related to the effects of larval density, temperature and sex on pupal development time (measured as the period between pupation and adult eclosion) of black soldier fly larvae. Pupae were kept in the same respective temperature treatments until pupation, 23,27 and $30^{\circ} \mathrm{C}$. See Table 2 for details.

Effect

Larval density $^{1}$

Temperature ${ }^{2}$

Sex $^{3}$

Larval density $\times \mathrm{Sex}^{4}$ df

2,9

2,693

1,621

2,695
$\mathbf{F}$

$\begin{array}{rr}1.4 & <0.0001 \\ 9.1 & <0.0001 \\ 749.7 & <0.0001 \\ 10.6 & 0.0015\end{array}$

${ }^{1}$ Shorter pupal period in the low-density treatment than in other density treatments.

2 Shorter pupal period in high- and medium-temperature treatments compared to the low-temperature treatment.

${ }^{3}$ Shorter pupal period in males than in females.

${ }^{4}$ Pupal period differences between the low-density treatment and other density treatments greater in males than in females. 


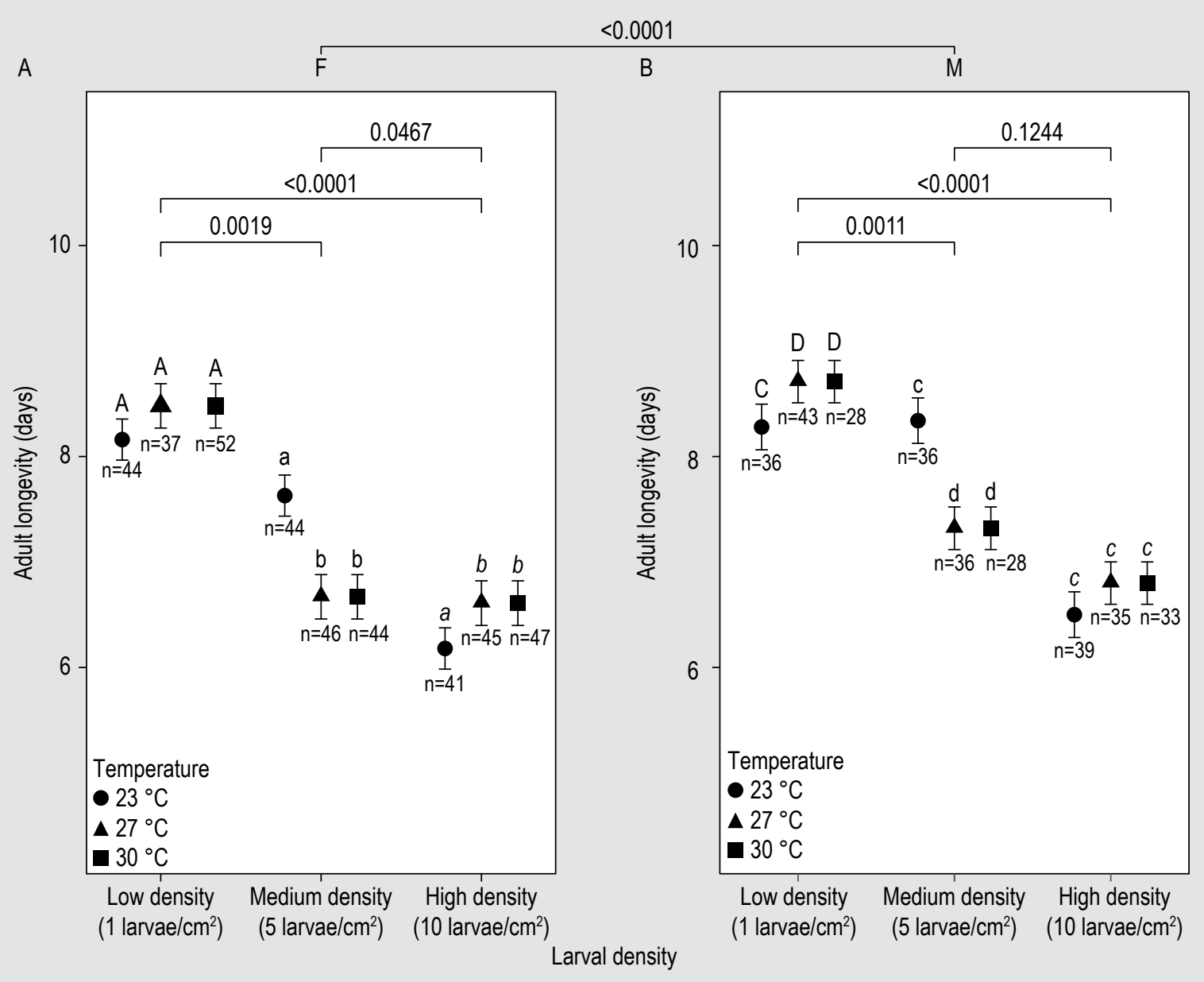

Figure 8. Adult longevity of the black soldier fly, measured as time from eclosion until death. Adults from all treatments were kept at $27^{\circ} \mathrm{C}$ during the entire adult period. See Figures 1 and 2 for details.

Table 8. Results of the linear mixed model related to the effects of larval density, temperature and sex on adult longevity of the black soldier fly (measured as time from eclosion until death). Adults from all treatments were kept at $27^{\circ} \mathrm{C}$ during the entire adult period. See Table 2 for details.

Effect

Larval density $^{1}$

Temperature

Sex ${ }^{2}$

Larval density $x$ Temperature ${ }^{3}$ df
2,9
2,693
1,688

4,693
$\mathbf{F}$

44.3

0.1

17.1

13.0
$<0.0001$

0.8960

$<0.0001$

$<0.0001$

${ }^{1}$ Adult period was longer in the low-density treatment compared to the medium- and high-density treatments.

${ }^{2}$ Adult period was longer in males than in females.

${ }^{3}$ Adult period was longer in the low-temperature treatment at medium density, but not at low and high densities. 


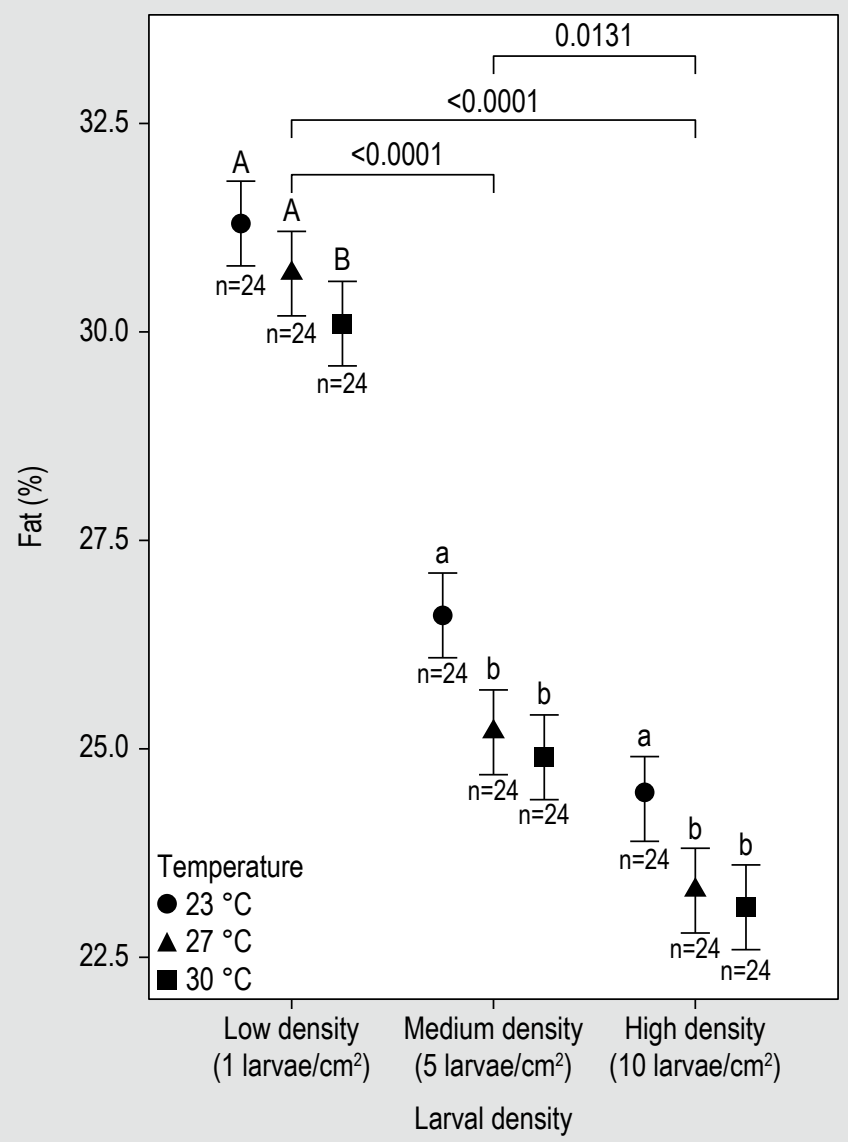

Figure 9. Percentage of fat in prepupae of the black soldier fly. See Figures 1 and 2 for details.

Table 9. Results of the ANOVA related to the effects of larval density and temperature on fat content of black soldier fly prepupae. See Table 2 for details.

$\begin{array}{llrr}\text { Effect } & \text { df } & \text { F } & \text { P } \\ & & & <0.0001 \\ \text { Larval density }^{1} & 2,9 & 157.4 & 0.1310 \\ \text { Temperature }^{2,198} & 2.1 & <0.0001 \\ \text { Larval densityx Temperature }^{2} & 4,198 & 11.9 & \end{array}$

\footnotetext{
${ }^{1}$ Fat content was higher in the low-density treatment than other density treatments, and higher in the medium-density compared to high-density treatment.

${ }^{2}$ At medium and high densities, fat content was higher at a low temperature than in other temperature treatments, but at low density, fat content was lower at a high temperature than in other temperature treatments.
}

shorter, on average) larval period than their counterparts reared at medium and high densities (Table 6, Figure 6). Larvae at medium larval density also developed faster $(7 \%$ shorter larval period, on average) than those reared at high larval densities. BSF larvae are naturally found in decaying organic waste material such as faeces (Sheppard et al., 1994). In this case, larval crowding may be beneficial as it helps to break down their food faster and help in assimilation (Green et al., 2002). However, very high larval densities certainly have disadvantages, such as depletion of a food source (Applebaum and Heifetz, 1999; Tammaru et al., 2000), higher incidence of cannibalism (Pervez and Gupta, 2006; Porretta et al., 2016) and higher concentration of pathogens (Anderson and May, 1981; Wilson et al., 2002). It may thus be that the typical stress response dominates over a density-specific response when relatively high or very high densities are used, as is the case for all BSF studies so far. Alternatively, or additionally, other factors could have contributed to these results, including the potential between-treatment differences in texture and viscosity of 
the feeding medium (Gobbi et al., 2013), food quality and quantity (Spranghers et al., 2016), as well as pH of the feed. BSF larvae reared at a low larval density had significantly higher prepupal, pupal and adult masses than those reared at medium and high densities. Similar results have been observed in previous BSF studies (Barragan-Fonseca et al., 2018; Diener et al., 2009; Jones and Tomberlin, 2019; Parra Paz et al., 2015).

Whereas all other traits studied here pointed to a low density being optimal and a high density being a suboptimal environment for BSFs, mass loss at the prepupal stage showed the opposite pattern, indicating, thus, that optimal conditions may differ for different traits. Moreover, previous studies in insects have suggested that there may be benefits associated with increased larval densities. For example, higher larval densities have been reported to allow for larval aggregations, thereby providing protection at low temperatures (Rivers and Dahlem, 2014) and enhancing larval ability to digest food (Green et al., 2002).

We observed that fat content increased significantly as rearing density decreased. Larval density has previously been reported to strongly influence the protein and fat compositions of the BSF (Barragan-Fonseca et al., 2017, 2018; Holmes et al., 2013; Myers et al., 2008; Spranghers et al., 2016; Tomberlin et al., 2002). Barragan-Fonseca et al. (2018) concluded that the protein content of BSF larvae tends to remain constant across different larval densities, but in contrast, fat content tends to vary inversely with other body components, such as carbohydrates, across different larval densities. In this regard, rearing density could serve as a tool that could be used to increase fat content when needed systematically, a vital relationship that commercial rearing set-ups could use to their advantage. Regarding sex, female BSFs, in general, were significantly heavier than their male counterparts in almost all life-history traits except adult mass, but males matured and emerged before females. Males emerging before their female counterparts (protandry) has been confirmed as the dominant form of sexual bimaturism in insects (Teder et al., 2021). The study by Jones and Tomberlin (2019) on BSF larvae found similar results in all studied life-history traits, excluding adult mass, where the effect of sex was also found to be significant. The main difference between these studies, which may have also had an influence on results, were the larval densities used and the lack of maintenance of larval density. This also provides an avenue for further studies on the effects of different larval densities on adult traits, because larval densities could influence mating choice and fecundity.

Strong thermal effects on the BSF life-history traits studied here are not unexpected. Tomberlin et al. (2009) determined that the optimal rearing temperature of BSF larvae lies between $27^{\circ} \mathrm{C}$ and $36^{\circ} \mathrm{C}$, and our study ranges fall partly below this range. Together with the Tomberlin et al. (2009) study, our results add to current information on how different environmental factors, such as moisture (Cammack and Tomberlin, 2017), $\mathrm{pH}$ (Ma et al., 2018) and diet quality (Nguyen et al., 2013) influence the life history and fitness in this commercially important insect species. Moreover, and perhaps even more importantly at present when the interactions between environmental factors are not well understood in BSFs, we showed that temperature considerably modified the effects of larval density in all of the traits studied except survival and pupal development time. For example, it is possible to considerably increase the size of prepupae by rearing the larvae at a lower temperature $\left(23^{\circ} \mathrm{C}\right)$, but this only applies at low larval density. On the other hand, surprisingly, relative mass loss in the prepupal stage was highest at a low temperature and especially at low density. To obtain prepupae with a high fat content, one should rear BSF larvae at a low temperature $\left(23^{\circ} \mathrm{C}\right)$, especially when the larval density is medium or high. For successful rearing and effective production of BSFs, it is therefore essential to account for several environmental factors simultaneously.

In summary, understanding the effects of larval density is of essential importance in the context of insect farming for food and feed, a branch of agriculture that is predicted to develop rapidly in the near future (Berggren et al., 2019). However, it is essential to note that rearing BSFs at very low larval densities may not be economically feasible, and perhaps even not biologically possible, as larvae of this species tend to aggregate at low densities. Therefore, understanding the effects of densities on life-history traits and finding a balance between trade-offs, both biological and economical, will open the road to efficient management of commercial insect rearing.

\section{Supplementary material}

Supplementary material can be found online at https://doi. org/10.3920/JIFF2021.0147

Table S1. Average, maximum and minimum values of within container temperature at different larval densities.

\section{Acknowledgements}

We thank Ants Kaasik for advice in statistics, Toomas Tammaru for valuable comments on the manuscript and Robert Barry Davis for language editing. This study was supported by Estonian Research Council grant PRG741, the Academy of Finland (Project 324392) and Trinsect Solutions OÜ (funding the establishment and maintenance of the BSF population at the University of Tartu). We thank two anonymous reviewers for their comments and suggestions on this manuscript. 


\section{Conflict of interest}

The authors declare no conflict of interest.

\section{References}

Anderson, R.M. and May R.M., 1981. The population dynamics of microparasites and their invertebrate hosts. Philosophical Transactions of the Royal Society of London Series B - Biological Sciences 291: 451-524. https://doi.org/10.1098/rstb.1981.0005

Agnew, P., Haussy, C. and Michalakis., J., 2000. Effects of density and larval competition on selected life history traits of Culex pipiens quinquefasciatus (Diptera: Culicidae). Journal of Medical Entomology 37: 732-735. https://doi.org/10.1603/0022-258537.5.732

Angilletta, M.J., Steury T. D. and Sears M. W., 2004. Temperature, growth rate, and body size in ectotherms: fitting pieces of a lifehistory puzzle. Integrative and Comparative Biology, 44: 498-509. https://doi.org/10.1093/icb/44.6.498

Applebaum, S.W. and Heifetz, Y., 1999. Density-dependent physiological phase in insects. Annual Review of Entomology 44: 317-341. https://doi.org/10.1146/annurev.ento.44.1.317

Atkinson, D. and Sibly, R.M., 1997. Why are organisms usually bigger in colder environments? Making sense of a life history puzzle. Trends in Ecology and Evolution 12: 235-239. https://doi.org/10.1016/ S0169-5347(97)01058-6

Barragan-Fonseca, K.B., Dicke, M. and Van Loon, J., 2018. Influence of larval density and dietary nutrient concentration on performance, body protein, and fat contents of black soldier fly larvae (Hermetia illucens). Entomologia Experimentalis et Applicata 166: 761-770. https://doi.org/10.1111/eea.12716

Barragan-Fonseca, K.B., Dicke, M. and Van Loon, J., 2017. Nutritional value of the black soldier fly (Hermetia illucens $L$.) and its suitability as animal feed - a review. Journal of Insects as Food and Feed 3: 105-120. https://doi.org/10.3920/JIFF2016.0055

Bates, D., Mächler, M., Bolker, B. and Walker, S., 2015. Fitting linear mixed-effects models using lme4. Journal of Statistical Software 67: 1-48. https://doi.org/10.18637/jss.v067.i01

Bauerfeind, S., Fischer, K. and Larsson, S., 2005. Effects of food stress and density in different life stages on reproduction in a butterfly. Oikos 111: 514-524. https://doi.org/10.1111/j.00301299.2005.13888.x

Bekker, N.S., Heidelbach, S., Vestergaard, S.Z., Nielsen, M.E., RiisgaardJensen, M., Zeuner, E.J., Bahrndorff, S. and Eriksen, N.T., 2021. Impact of substrate moisture content on growth and metabolic performance of black soldier fly larvae. Waste Managemen 127: 73-79. https://doi.org/10.1016/j.wasman.2021.04.028

Berger, D., Olofsson, M., Gotthard, K., Wiklund, C. and Friberg, M., 2012. Ecological constraints on female fitness in a phytophagous insect. American Naturalist 180: 464-480. https://doi. org/10.1086/667594

Berggren, Å., Jansson, A. and Low, M., 2019. Approaching ecological sustainability in the emerging insects-as-food industry. Trends in Ecology and Evolution 34: 132-138. https://doi.org/10.1016/j. tree.2018.11.005
Bulak, P., Polakowski, C., Nowak, K., Waśko, A., Wiącek, D. and Bieganowski, A., 2018. Hermetia illucens as a new and promising species for use in entomoremediation. Science of the Total Environment 633: 912-919. https://doi.org/10.1016/j. scitotenv.2018.03.252

Cammack, J.A. and Tomberlin, J.K., 2017. The impact of diet protein and carbohydrate on select life-history traits of the black soldier fly Hermetia illucens (L.) (Diptera: Stratiomyidae). Insects 8: 56. https://doi.org/10.3390/insects8020056

Chia, S.Y., Tanga, C.M., Khamis, F.M., Mohamed, S.A., Salifu, D., Sevgan, S., Fiaboe, K.K.M., Niassy, S., Van Loon, J.J.A., Dicke, M. and Ekesi, S., 2018. Threshold temperatures and thermal requirements of black soldier fly Hermetia illucens: implications for mass production. PLoS ONE 13: 11. https://doi.org/10.1371/journal.pone.0206097

Couret, J., Dotson, E. and Benedict, M.Q., 2014. Temperature, larval diet, and density effects on development rate and survival of Aedes aegypti (Diptera: Culicidae). PLoS ONE 9: e87468. https://doi. org/10.1371/journal.pone.0087468

Diener, S., Zurbrügg, C. and Tockner, K., 2009. Conversion of organic material by black soldier fly larvae: establishing optimal feeding rates. Waste Management and Research 27: 603-610. https://doi. org/10.1177\%2F0734242X09103838

Diener, S., Zurbrügg, C., Gutiérrez, F., Nguyen, D., Morel, A., Koottatep, T. and Tockner, K., 2011. Black soldier fly larvae for organic waste treatment 2011 - prospects and constraints. In: Alamgir, M., Bari, Q.H., Rafizul, I.M., Islam, S.M.T., Sarkar, G. and Howlader, M.K. (eds.) Proceedings of the WasteSafe $2011-2^{\text {nd }}$ International Conference on Solid Waste Management in the Developing Countries. 13-15 February 2011. Khulna, Bangladesh.

Dörper, A., Veldkamp, T. and Dicke, M., 2021. Use of black soldier fly and house fly in feed to promote sustainable poultry production. Journal of Insects as Food and Feed 7: 761-780. https://doi. org/10.3920/JIFF2020.0064

Dzepe, D., Nana, P., Kuietche, H.M., Kuate, A., Tchuinkam, T. and Djouaka, R., 2020. Role of pupation substrate on post-feeding development of black soldier fly larvae, Hermetia illucens (Diptera: Stratiomyidae). Journal of Entomological and Zoology Studies 8: 760-764. https://doi.org/10.1603/EN12255

Esperk, T., Tammaru, T. and Nylin, S., 2007. Intraspecific variability in number of larval instars in insects. Journal of Economic Entomology 100: 627-645. https://doi.org/10.1093/jee/100.3.627

Ezeakacha, N.F. and Yee, D.A., 2019. The role of temperature in affecting carry-over effects and larval competition in the globally invasive mosquito Aedes albopictus. Parasites and Vectors 12: 123. https://doi.org/10.1186/s13071-019-3391-1

Fantinou, A.A., Perdikis, D.C. and Stamogiannis, N., 2008. Effect of larval crowding on the life history traits of Sesamia nonagrioides (Lepidoptera: Noctuidae). European Journal of Entomology 105: 625-630. https://doi.org/10.14411/eje.2008.084

Flockhart, D.T.T., Martin, T.G. and Norris, D.R., 2012. Experimental examination of intraspecific density-dependent competition during the breeding period in monarch butterflies (Danaus plexippus). PLoS ONE 7: e45080. https://doi.org/10.1371/journal.pone.0045080 
Gibbs, M., Lace, L.A., Jones, M.J. and Moore, A.J., 2004. Intraspecific competition in the speckled wood butterfly Pararge aegeria: effect of rearing density and gender on larval life history. Journal of Insect Science 4: 16. https://doi.org/10.1093\%2Fjis\%2F4.1.16

Gligorescu, A., Toft, S., Hauggaard-Nielsen, H., Axelsen, J.A. and Nielsen, S.A., 2018. Development, metabolism and nutrient composition of black soldier fly larvae (Hermetia illucens; Diptera: Stratiomyidae) in relation to temperature and diet. Journal of Insects as Food and Feed 4: 123-133. https://doi.org/10.3920/JIFF2017.0080

Gobbi, P.A., Martínez-Sánchez, A.N. and Rojo, S.A., 2013. The effects of larval diet on adult life-history traits of the black soldier fly, Hermetia illucens (Diptera: Stratiomyidae). European Journal of Entomology 110: 461-468. https://doi.org/10.14411/eje.2013.061

Gravel, A. and Doyen, A., 2020. The use of edible insect proteins in food: challenges and issues related to their functional properties. Innovative Food Science and Emerging Technologies 59: 102272. https://doi.org/10.1016/j.ifset.2019.102272

Green, P.W., Simmonds, M.S. and Blaney, W.M., 2002. Does the size of larval groups influence the effect of metabolic inhibitors on the development of Phormia regina (Diptera: Calliphoridae) larvae. European Journal of Entomology 99: 19-22. https://doi. org/10.14411/eje.2002.005

Halekoh, U. and Højsgaard, S., 2014. A Kenward-Roger approximation and parametric bootstrap methods for tests in linear mixed models - the R package pbkrtest. Journal of Statistical Software 59: 1-32. https://doi.org/10.18637/jss.v059.i09

Harvey, J.A., Poelman, E.H. and Tanaka, T., 2013. Intrinsic interand intraspecific competition in parasitoid wasps. Annual Review of Entomology 58: 333-351. https://doi.org/10.1146/annurevento-120811-153622

Harnden, L.M. and Tomberlin, J.K., 2016. Effects of temperature and diet on black soldier fly, Hermetia illucens (L.) (Diptera: Stratiomyidae), development. Forensic Science International 266: 109-116. https://doi.org/10.1016/j.forsciint.2016.05.007

Holmes, L.A., Vanlaerhoven, S.L. and Tomberlin, J.K., 2013. Substrate effects on pupation and adult emergence of Hermetia illucens (Diptera: Stratiomyidae). Environmental Entomology 42: 370-374. https://doi.org/10.1603/EN12255

Issimov, A., Taylor, D.B., Zhugunissov, K., Kutumbetov, L., Zhanabayev, A., Kazhgaliyev, N., Akhmetaliyeva, A., Nurgaliyev, B., Shalmenov, M., Absatirov, G., Dushayeva, L. and White, P.J., 2020. The combined effects of temperature and relative humidity parameters on the reproduction of Stomoxys species in a laboratory setting. PLoS ONE 15: 12. https://doi.org/10.1371/journal.pone.0242794.

Jiang, Q., Han, J., Gao, P., Yu, L., Xu, Y. and Xia, W., 2018. Effect of heating temperature and duration on the texture and protein composition of bighead carp (Aristichthys nobilis) muscle. International Journal of Food Properties 21: 2110-2120. https:// doi.org/10.1080/10942912.2018.1489835

Jones, B.M. and Tomberlin, J.K., 2019. Impact of larval competition on life-history traits of the black soldier fly (Diptera: Stratiomyidae). Annals of the Entomological Society of America 112: 505-510. https://doi.org/10.1093/aesa/saz014.
Jonsson, B., Jonsson, N. and Finstad, A.G., 2013. Effects of temperature and food quality on age and size at maturity in ectotherms: an experimental test with Atlantic salmon. Journal of Animal Ecology 82: 201-210. https://doi.org/10.1111/j.1365-2656.2012.02022.x

Joosten, L., Lecocq, A., Jensen, A.B., Haenen, O., Schmitt, E. and Eilenberg, J., 2020. Review of insect pathogen risks for the black soldier fly (Hermetia illucens) and guidelines for reliable production. Entomologia Experimentalis et Applicata 168: 432-447. https://doi. org/10.1111/eea.12916

Kawecki, T.J. and Stearns, S.C., 1993. The evolution of life histories in spatially heterogeneous environments: optimal reaction norms revisited. Evolutionary Ecology 7: 155-174. https://doi.org/10.1007/ BF01239386

Kilara, A. and Sharkasi, T.Y., 1986. Effects of temperature on food proteins and its implications on functional properties. Critical Reviews in Food Science and Nutrition 23: 323-395. https://doi. org/10.1080/10408398609527429

Kim, W., Bae, S., Park, H., Park, K., Lee, S., Choi, Y., Han, S. and Koh, Y., 2010. The larval age and mouth morphology of the black soldier fly, Hermetia illucens (Diptera: Stratiomyidae). International Journal of Industrial Entomology 21: 185-187.

Kingsolver, J.G. and Huey, R.B., 2008. Size, temperature, and fitness: three rules. Evolutionary Ecology Research 10: 251-268.

Kuznetsova, A., Brockhoff, P.B. and Christensen, R.H.B., 2017. ImerTest Package: tests in linear mixed effects models. Journal of Statistical Software 82: 1-26. https://doi.org/10.18637/jss.v082.i13

Liland, N.S., Araujo, P., Xu, X.X., Lock, E.-J., Radhakrishnan, G., Prabhu, A.J.P. and Belghit, I., 2021. A meta-analysis on the nutritional value of insects in aquafeeds. Journal of Insects as Food and Feed 7: 743759. https://doi.org/10.3920/JIFF2020.0147

Lyimo, E.O., Takken, W. and Koella, J.C., 1992. Effect of rearing temperature and larval density on larval survival, age at pupation and adult size of Anopheles gambiae. Entomologia Experimentalis et Applicata 63: 265-271. https://doi.org/10.1111/j.1570-7458.1992. tb01583.x

Ma, J., Lei, Y., Rehman, K.U., Yu, Z., Zhang, J., Li, W., Li, Q., Tomberlin, J.K. and Zheng, L., 2018. Dynamic effects of initial pH of substrate on biological growth and metamorphosis of black soldier fly (Diptera: Stratiomyidae). Environmental Entomology 47: 159-165. https:// doi.org/10.1093/ee/nvx186

Malhi, Y., Franklin, J., Seddon, N., Solan, M., Turner, M.G., Field, C.B. and Knowlton, N., 2020. Climate change and ecosystems: threats, opportunities and solutions. Philosophical Transactions of the Royal Society B 375: 20190104. https://doi.org/10.1098/rstb.2019.0104.

Mamai, W., Lobb, L.N., Bimbilé Somda, N.S., Maiga, H., Yamada, H., Lees, R.S., Bouyer, J. and Gilles, J., 2018. Optimisation of massrearing methods for Anopheles arabiensis larval stages: effects of rearing water temperature and larval density on mosquito lifehistory traits. Journal of Economic Entomology 111: 2383-2390. https://doi.org/10.1093/jee/toy213

Marr Linsey, C., Tang Julian, W., Van Mullekom, J. and Lakdawala Seema, S., 2019. Mechanistic insights into the effect of humidity on airborne influenza virus survival, transmission and incidence. Journal of the Royal Society Interface 16: 20180298. https://doi. org/10.1098/rsif.2018.0298 
Matiu, M., Ankerst, D.P. and Menzel, A., 2017. Interactions between temperature and drought in global and regional crop yield variability during 1961-2014. PLoS ONE 12: e0178339. https://doi.org/10.1371/ journal.pone.0178339

Mertenat, A., Diener, S. and Zurbrügg, C., 2019. Black soldier fly biowaste treatment - assessment of global warming potential. Waste Management 84: 173-181. https://doi.org/10.1016/j. wasman.2018.11.040

Myers, H.M., Tomberlin, J.K., Lambert, B.D. and Kattes, D., 2008. Development of black soldier fly (Diptera: Stratiomyidae) larvae fed dairy manure. Environmental Entomology 37: 11-15. https:// doi.org/10.1093/ee/37.1.11

Nakagaki, B.J. and DeFoliart, G.R., 1991. Comparison of diets for mass-rearing Acheta domesticus (Orthoptera: Gryllidae) as a novelty food, and the comparison of food conversion efficiency with values reported for livestock. Journal of Economic Entomology 84: 891896. https://doi.org/10.1093/jee/84.3.891

Nardoni Laws, A. and Belovsky, G.E., 2010. How will species respond to climate change? Examining the effects of temperature and population density on an herbivorous insect. Environmental Entomology 39: 312-319. https://doi.org/10.1603/EN09294.

Nguyen, T.T., Tomberlin, J.K. and Vanlaerhoven, S., 2013. Influence of resources on Hermetia illucens (Diptera: Stratiomyidae) larval development. Journal of Medical Entomology 50: 898-906. https:// doi.org/10.1603/me12260

Oonincx, D.G.A.B., Van Broekhoven, S., Van Huis, A. and Van Loon, J.J.A., 2015. Feed conversion, survival and development, and composition of four insect species on diets composed of food by-products. PLoS ONE 14: e222043. https://doi.org/10.1371/ journal.pone.0144601

Parra Paz, A.S., Carrejo, N.S. and Gómez Rodríguez, C.H., 2015. Effects of larval density and feeding rates on the bioconversion of vegetable waste using black soldier fly larvae Hermetia illucens (L.), (Diptera: Stratiomyidae). Waste and Biomass Valorisation 6: 1059-1065. https://doi.org/10.1007/s12649-015-9418-8

Payne, L.R., Scarborough, P., Rayner, M. and Nonaka, K., 2016. A systematic review of nutrient composition data available for twelve commercially available edible insects, and comparison with reference value. Trends in Food Science and Technology 47: 69-77. https://doi.org/10.1016/j.tifs.2015.10.012

Pener, M.P. and Simpson, S.J., 2009. Locust phase polyphenism: an update. Advances in Insect Physiology 36: 1-289. https://doi. org/10.1016/S0065-2806(08)36001-9

Pervez, A., Gupta, A.K. and Omkar, 2006. Larval cannibalism in aphidophagous ladybirds: influencing factors, benefits and costs. Biological Control 38: 307-313. https://doi.org/10.1016/j. biocontrol.2006.04.013

Porretta, D., Mastrantonio, V., Crasta, G., Bellini, R., Comandatore, F., Rossi, P., Favia, G., Bandi, C. and Urbanelli, S., 2016. Intra-instar larval cannibalism in Anopheles gambiae (s.s.) and Anopheles stephensi (Diptera: Culicidae). Parasites and Vectors 9: 566. https:// doi.org/10.1186/s13071-016-1850-5

R Core Team, 2020. R: a language and environment for statistical computing. R Foundation for Statistical Computing, Vienna, Austria. Available at: https://www.r-project.org/
Raimondi, S., Spampinato, G., Macavei, L.I., Lugli, L., Candeliere, F., Rossi, M., Maistrello, L. and Amaretti, A., 2020. Effect of rearing temperature on growth and microbiota composition of Hermetia illucens. Microorganisms 8: 902. https://doi.org/10.3390/ microorganisms 8060902

Reigada, C. and Godoy, W.C., 2006. Larval density, temperature and biological aspects of Chrysomya megacephala (Diptera: Calliphoridae). Arquivo Brasileiro de Medicina Veterinária e Zootecnia 58: 562-566. https://doi.org/10.1590/S010209352006000400018

Remmel, T., Davison, J. and Tammaru, T., 2010. Quantifying predation on folivorous insect larvae: the perspective of life-history evolution. Biological Journal of the Linnean Society 104: 1-18. https://doi. org/10.1111/j.1095-8312.2011.01721.x

Rivers, D.B. and Dahlem, G.A., 2014. The science of forensic entomology. John Wiley \& Sons, Hoboken, NJ, USA.

Rumpold, B.A. and Schlüter, O.K., 2013. Nutritional composition and safety aspects of edible insects. Molecular Nutrition and Food Research 57: 802-823. https://doi.org/10.1002/mnfr.201200735

Satterthwaite, F.E., 1946. An approximate distribution of estimates of variance components. Biometrics Bulletin. 2: 110. https://doi. org/10.2307/3002019

Schrader, M., Jarrett, B.J. and Kilner, R.M., 2015. Parental care masks a density-dependent shift from cooperation to competition among burying beetle larvae. Evolution 69: 1077-1084. https://dx.doi. org/10.1111\%2Fevo.12615

Skendžić, S., Zovko, M., Živković, I.P., Lešić, V. and Lemić, D., 2021. The impact of climate change on agricultural insect pests. Insects 12: 440. https://doi.org/10.3390/insects 12050440

Searle, S.R., Speed, F.M. and Milliken, G.A., 1980. Population marginal means in the linear model: an alternative to least squares means. The American Statistician 34: 216-221. https://doi.org/10.1080/0 0031305.1980.10483031

Sehgal A., Sita K., Kumar J., Kumar S., Singh S., Siddique K.H.M. and Nayyar H., 2017. Effects of drought, heat and their interaction on the growth, yield and photosynthetic function of lentil (Lens culinaris medikus) genotypes varying in heat and drought sensitivity. Frontiers in Plant Science 8: 1776. https://doi.org/10.3389/fpls.2017.01776

Shishkov, O. and Hu, D.L., 2020. Synchronising pile formation of black soldier fly larvae. The European Physical Journal Special Topics 229: 2779-2789. https://doi.org/10.1140/epjst/e2020-900264-y

Shishkov, O., Hu, M., Johnson, C. and Hu, D.L., 2019. Black soldier fly larvae feed by forming a fountain around food. Journal of the Royal Society Interface 16: 20180735. https://doi.org/10.1098/ rsif.2018.0735

Sheppard, C., Newton, G.L., Thompson, S.A. and Savage, S., 1994. A value-added manure management system using the black soldier fly. Bioresource and Technology 50: 275-279.

Spranghers, T., Ottoboni, M., Klootwijk, C., Ovyn, A., Deboosere, S., De Meulenaer, B., Michiels, J., Eeckhout, M., De Clercq, P. and De Smet, S., 2016. Nutritional composition of black soldier fly (Hermetia illucens) prepupae reared on different organic waste substrates. Journal of the Science of Food and Agriculture 97: 25942600. https://doi.org/10.1002/jsfa.8081 
Stock, S.P., Vandenburg, J., Glazer, I. and Boemare, N., 2009. Insect pathogens: molecular approaches and techniques. $\mathrm{CAB}$ International, Wallingford, UK.

Su, C.H., Hoang, C.N., Thi, L.B. and Deng-Liang, H., 2019. Enzymeassisted extraction of insect fat for biodiesel production. Journal of Cleaner Production 223: 436-444. https://doi.org/10.1016/j. jclepro.2019.03.150

Tammaru, T., Ruohomäki, K. and Montola, M., 2000. Crowding-induced plasticity in Epirrita autumnata (Lepidoptera: Geometridae): weak evidence of specific modifications in reaction norms. Oikos 90: 171-181. https://doi.org/10.1034/j.1600-0706.2000.900117.x

Tammaru, T., Vellau, H., Esperk, T. and Teder, T. 2015. Searching for constraints by cross-species comparison: reaction norms for age and size at maturity in insects. Biological Journal of the Linnean Society 114: 296-307. https://doi.org/10.1111/bij.12417

Teder, T., Kaasik, A., Taits, K. and Tammaru, T., 2021. Why do males emerge before females? Sexual size dimorphism drives sexual bimaturism in insects. Biological Reviews 96: 2461-2475. https:// doi.org/10.1111/brv.12762

Teder, T., Vellau, H. and Tammaru, T., 2014. Age and size at maturity: a quantitative review of diet-induced reaction norms in insects. Evolution 68: 3217-3228. https://doi.org/10.1111/evo.12518

Than, A.T., Ponton, F. and Morimoto, J., 2020. Integrative developmental ecology: a review of density-dependent effects on life-history traits and host-microbe interactions in non-social holometabolous insects. Evolutionary Ecology 34: 659-680. https://doi.org/10.1007/s10682020-10073-x

Tomberlin, J.K. and Van Huis, A., 2020. Black soldier fly from pest to 'crown jewel' of the insects as feed industry: an historical perspective. Journal of Insects as Food and Feed 6: 1-4. https://doi.org/10.3920/ JIFF2020.0003

Tomberlin, J.K., Adler, P.H. and Myers, H.M., 2009. Development of the black soldier fly (Diptera: Stratiomyidae) in relation to temperature. Environmental Entomology 38: 930-934. https:// doi.org/10.1603/022.038.0347

Tomberlin, J.K., Sheppard, D.C. and Joyce, J.A., 2002. Selected life history traits of black soldier flies (Diptera: Stratiomyidae) reared on three artificial diets. Annals of the Entomological Society of America 95: 379-386.

Van Huis, A., 2013. Potential of insects as food and feed in assuring food security. Annual Review of Entomology 58: 563-583. https:// doi.org/10.1146/annurev-ento-120811-153704
Van Huis, A. and Oonincx, D.G.A.B., 2017. The environmental sustainability of insects as food and feed. A review. Agronomy for Sustainable Development 37: 43. https://doi.org/10.1007/s13593017-0452-8

Veldkamp, T. and Vernooij, A.G., 2021. Use of insect products in pig diets. Journal of Insects as Food and Feed 7: 781-793. https://doi. org/10.3920/JIFF2020.0091

Vellau, H. and Tammaru, T., 2012. Larval crowding leads to unusual reaction norms for size and time at maturity in a geometrid moth (Lepidoptera: Geometridae). European Journal of Entomology 109: 181-186. https://doi.org/10.14411/eje.2012.024

Venancio, L.P., Filgueiras, R., Mantovani, E.C., Do Amaral, C.H., Da Cunha, F.F., Dos Santos Silva, F.C., Althoff, D., Dos Santos, R.A. and Cavatte, P.C., 2020. Impact of drought associated with high temperatures on Coffea canephora plantations: a case study in Espírito Santo State, Brazil. Scientific Reports 10: 19719. https:// doi.org/10.1038/s41598-020-76713-y.

Wang, H., Rehman, K.U. and Liu, X., 2017. Insect biorefinery: a green approach for conversion of crop residues into biodiesel and protein. Biotechnology for Biofuels 10: 304. https://doi.org/10.1186/s13068017-0986-7

Wegier, A., Alavez, V., Pérez-López, J., Calzada, L. and Cerritos, R., 2018. Beef or grasshopper hamburgers: the ecological implications of choosing one over the other. Basic and Applied Ecology 26: 89100. https://doi.org/10.1016/j.baae.2017.09.004

Wilson, K., 2002. Ups and downs of wildlife population regulation by macroparasites. Trends in Ecology and Evolution 17: 454. https:// doi.org/10.1016/S0169-5347(02)02607-1

Wilson, K. and Cotter, S.C., 2009. Density-dependent prophylaxis in insects. In: Ananthakrishnan, T.N. and Whitman, T.W. (eds.) Phenotypic plasticity of insects: mechanisms and consequences. Science Publsihers Inc., Enfield, CT, USA, pp. 381-420.

Wong, C., Siti-Suhailah, R., Yoshimitsu, U., Yeek, C., Arunsri, L., Worapon, K., Chin-Kui, C., Man-Kee, L. and Jun-Wei, L., 2019. Potential protein and biodiesel sources from black soldier fly larvae: insights of larval harvesting instar and fermented feeding medium. Energies 12: 8. https://doi.org/10.3390/en12081570

Zapletal, J., Erraguntla, M., Adelman, Z.N., Myles, K.M. and Lawley, M.A., 2018. Impacts of diurnal temperature and larval density on aquatic development of Aedes aegypti. PLoS ONE 13: e0194025. https://doi.org/10.1371/journal.pone.0194025 